\title{
Molecular mechanisms and clinical manifestations of rare genetic disorders associated with type I collagen
}

\author{
Yanqin Lu ${ }^{1,2, *}$, Shie Zhang ${ }^{1,2}$, Yanzhou Wang ${ }^{3}$, Xiuzhi Ren ${ }^{4}$, Jinxiang Han ${ }^{1,2}$ \\ ${ }^{1}$ Key Laboratory for Biotech-Drugs of National Health Commission, Key Laboratory for Rare \& Uncommon Diseases of \\ Shandong Province, Shandong Medicinal Biotechnology Centre, Shandong First Medical University \& Shandong Academy of \\ Medical Sciences, Ji'nan, China; \\ ${ }^{2}$ School of Medicine and Life Sciences, University of Jinan-Shandong Academy of Medical Sciences, Ji'nan, China; \\ ${ }^{3}$ Shandong Provincial Hospital Affiliated to Shandong First Medical University, Ji'nan, China; \\ ${ }^{4}$ Department of Orthopaedic Surgery, The People's Hospital of Wuqing District, Tianjin, China.
}

\begin{abstract}
Summary Type I collagen is an important structural protein of bone, skin, tendon, ligament and other connective tissues. It is initially synthesized as a precursor form, procollagen, consisting of two identical pro-a1(I) and one proo2(I) chains, encoded by COL1A1 and COL1A2, respectively. The $\mathrm{N}$ - and $\mathrm{C}$ - terminal propeptides of procollagen are cleavage by $\mathrm{N}$-proteinase and $\mathrm{C}$-proteinase correspondingly, to form the central triple helix structure with Gly-X-Y repeat units. Mutations of $C O L 1 A 1$ and $C O L 1 A 2$ genes are associated with osteogenesis imperfecta, some types of Ehlers-Danlos syndrome, Caffey diseases, and osteogenesis imperfect/EhlersDanlos syndrome overlapping diseases. Clinical symptoms caused by different variations can be variable or similar, mild to lethal, and vice versa. We reviewed the relationship between clinical manifestations and type I collagen - related rare genetic disorders and their possible molecular mechanisms for different mutations and disorders.
\end{abstract}

Keywords: Type I collagen, biosynthesis, osteogenesis imperfecta, Ehlers-Danlos syndrome, Caffey disease, $\mathrm{N}$ - and $\mathrm{C}$ - propeptide, mutation

\section{Introduction}

Type I collagen, as an important structural protein, is classified as one of the major fibrillar collagens (1). It is the most common collagen found in the human body and other vertebrates. Type I collagen is distributed widely, including bones, ligaments, tendons, cartilage, skin, liver, heart valves, cornea, lungs and other connective tissues $(2,3)$. It is synthesized as procollagen precursor, which predominately consists of two identical proa1(I) and one proo2(I) peptide chains, encoded by COL1A1 and $C O L 1 A 2$ gene, respectively. Three $\alpha$-chains fold into a $300 \mathrm{~nm}$-long triple helix with short nonhelical terminal peptides-telopeptides. The triple helical region of each $\alpha$-chain has the obligatory Gly-X-Y repeats with glycine in every third position. The amino acids

\footnotetext{
*Address correspondence to:

Dr. Yanqin Lu, Shandong First Medical University \& Shandong Academy of Medical Sciences, 18877 Jingshi Road, Ji'nan 250062, China.

E-mail: yanqinlu@yahoo.com
}

in $\mathrm{X}$ and $\mathrm{Y}$ position of collagen are often proline and hydroxyproline, respectively $(4,5)$.

The heterotrimer is the dominant form of type I collagen. Homotrimers of three $\alpha 1(\mathrm{I})$ chains are identified in fetal tissues, tumors and some fibrotic lesions and this isoform is more resistant to cleavage by collagenases than heterotrimers (6-9). In a recessively homozygous oim mice with $\mathrm{G}$ deletion at nucleotide 3983 of COL1A2 gene, and recessively cardiac valvular type Ehlers-Danlos syndrome (cvEDS), collagen molecules exist as homotrimers of three $\alpha 1$ (I) in the extracellular matrix and proa2(I) chains are not incorporated into procollagen molecules (10-12).

Mutations in COL1A1 and COL1A2 genes cause Caffey disease (OMIM 114000) (13), the arthrochalasia type Ehlers-Danlos syndrome (aEDS) (OMIM 130060, 617821) (14-16), cvEDS is an autosomal recessive genetic form (OMIM 225320) (12) and autosomal dominant osteogenesis imperfecta (OI) (OMIM 166200, $166210,259420,166220)$, postmenopausal osteoporosis (OMIM 166710) (17). Symptomatic patients with different or similar clinical phenotypes are described 


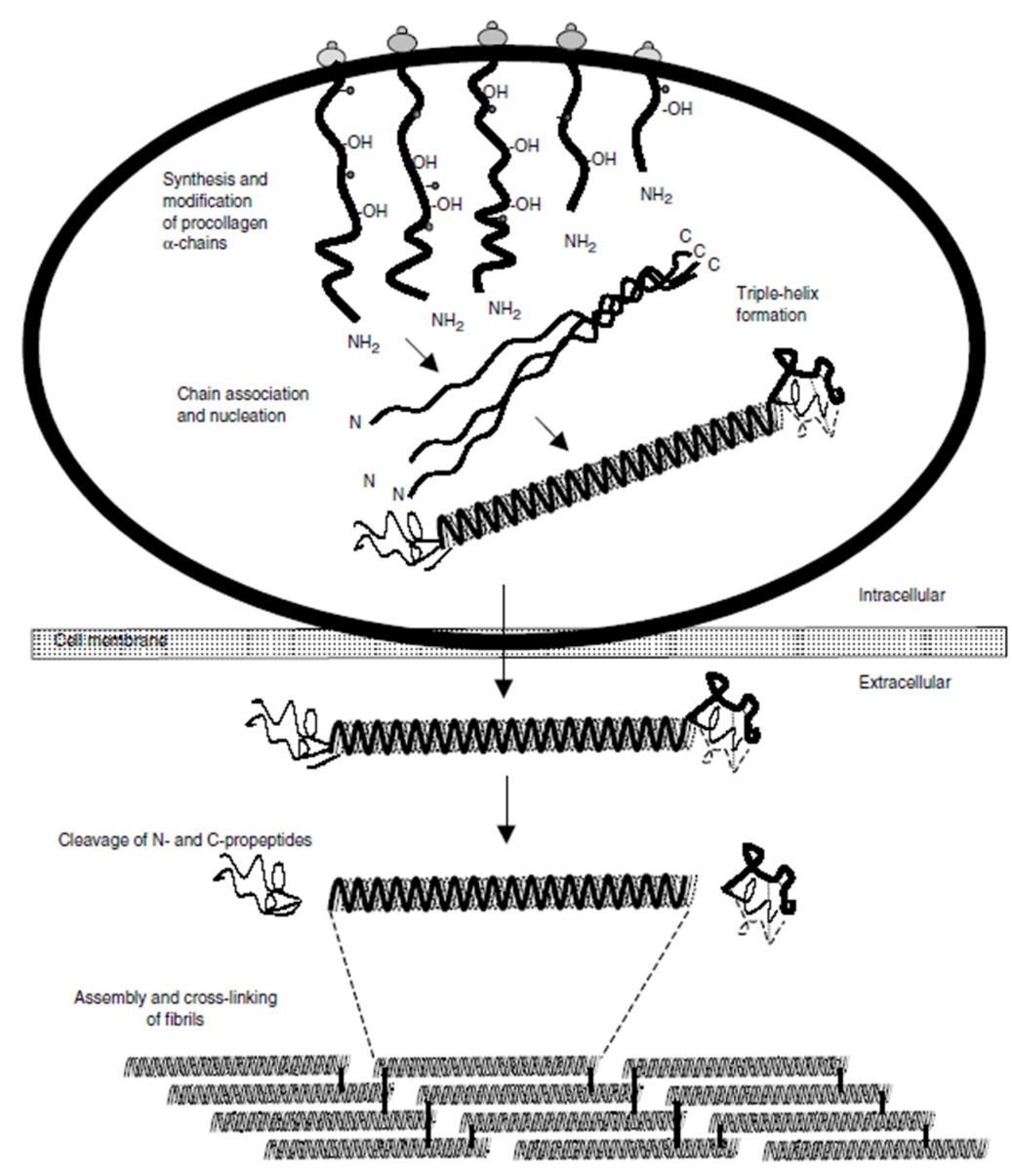

Figure 1. Schematic representation in the process of synthesis, processing and assembly of type I collagen (18).

in different disorders and mutations. Subclinical or asymptomatic individuals with these inherited diseases may express an overlap syndrome, or different penetrance and expressivity in patients with the same pathogenic mutations.

This review summarizes the biosynthesis process of type I collagen and investigates the correaltionship between phenotype and genotype and mechanisms of rare genetic disorders related to COL1A1 and COL1A2.

\section{Biosynthesis of type I collagen}

The process of type I collagen biosynthesis undergoes multiple intracellular and extracellular steps (Figure 1) (18). First, procollagen is synthesized on the ribosome and transported into the rough endoplasmic reticulum (rER), where they undergo a series of post-translational modifications. Hydroxylation of prolyl and lysyl residues are catalyzed by prolyl 4/3-hydroxylases $(\mathrm{P} 4 \mathrm{H}, \mathrm{P} 3 \mathrm{H})$ and lysyl hydroxylases $(\mathrm{LH})$, respectively (19). O-linked glycosylation of hydroxylysines is followed by the attachment of galactose and then glucose to hydroxylysine residues. These modifications are processed simultaneously with the synthesis and folding of procollagen chains and occur only within the unfolded region of the chains (20-22). Unlike most proteins, which begin to fold stepwise from $\mathrm{N}$-terminal end to C-terminal end while the rest of the chain is still being synthesized.

The folding process of procollagen initiates from association of two proa1(I) and one proa2(I) peptide chain within $\mathrm{C}$-propeptide region, then stepwise to $\mathrm{N}$-terminal end of the chain. C-propeptide folds in a zipper-like manner only after chain synthesis is completed (21). Chain recognition sequences (CRSs) of the C-propeptide is involved in the process of folding. It interacts with the CRSs of a neighboring chain during intracellular trimerization of procollagen to ensure correct homotrimeric and heterotrimeric chain stoichiometry (23). CRSs is variable and responsible for selective assembly of different types of collagen $(23,24)$. Meanwhile, protein disulfide isomerase (PDI) catalyzes the formation and rearrangement of intra- and inter-molecular disulfide bonds (25). There are many other proteins involved in the procollagen assembly. ER chaperones like glucose regulated proteins GRP78 (BiP) and GRP94 (GP96) bind to unfolded and partially folded C-propeptide. Misfolding procollagen leads to sequestration of BiP and GRP94, activates conventional unfolded protein response (UPR) signaling, and leads to ER associated degradation (ERAD) of misfolded protein by proteasomes (26-29). Heat shock protein 47 (HSP47), 


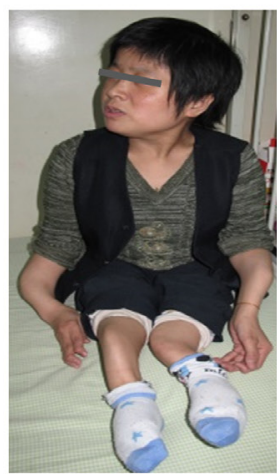

A

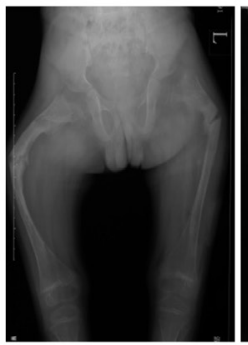

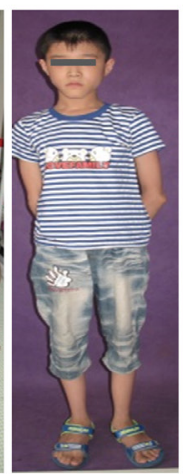

B

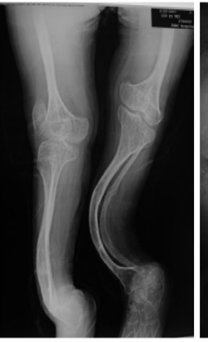

b
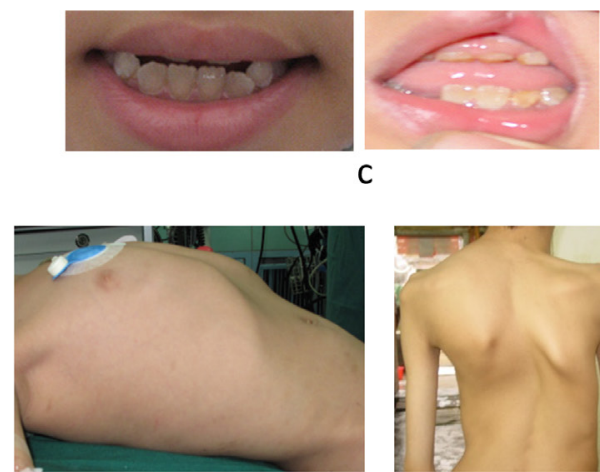

D

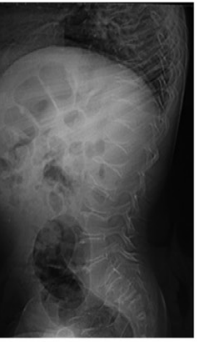

C

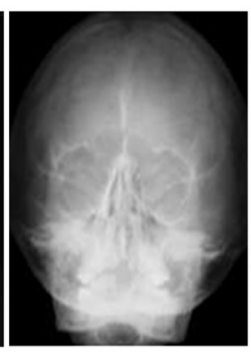

d

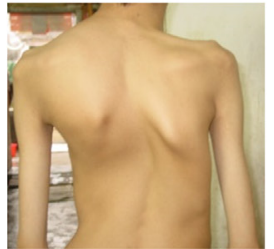

$E$

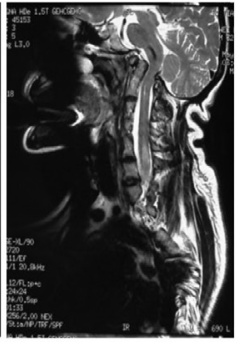

e

Figure 2. Clinical phenotypes (A-E) and radiographic characteristics (a-e) for OI. (A), type III patient (32 years old); (B), type IV patient (14 years old); (C), tooth abnormality; (D), pectus carinatum; (E), scoliosis; a. angular deformity of bilateral femurs, thin cortical bone; b. popcorn metaphyses; c. compression of spinal vertebrae; d. wormian bone; e. basilar impression.

as a collagen-specific molecular chaperone, makes the triplex-helix folding favorable (30). It regulates LH2 activity through association to peptidyl-prolyl cis-trans isomerase (FKBP65) and LH2 to form HSP47-FKBP65LH2-BiP complex. FKBP65, interacting with HSP47, functions to balance the lysyl hydroxylation. BiP increases affinity of the lysyl hydroxylation complex (31).

After assembly, procollagen is transported into Golgi through endoplasmic reticulum to Golgi intermediate compartment (ERGIC), or vesicular tubular clusters (VRC) in a coat protein complex II (COPII)-dependent process. ER membrane protein TANGO1, acts as the receptor for large cargoes- procollagen and organizer of ER exit sites. It is retained in the ER and exported out of the ER in large COPII -coated carriers, and retrieved back to the ER by retrograde coat, COPI. TANGO1 interacts with the C-terminal RDEL retrieval sequence of HSP47 and is exported from ER to Golgi through interacting proteins cTAGE5 and SEC12 (32-34).

In Golgi, N-propeptide and C-propeptide cleavage have been identified in the secretory pathway inside the cell (35). Nevertheless, a predominant fraction of procollagen is secreted with intact $\mathrm{N}$ - and C-propeptides into extracellular matrix (36). Then, N-terminal and $\mathrm{C}$-terminal globular regions of propeptides are removed by a disintegrin and a metalloproteinase with thrombospondin repeats (ADAMTS) and bone morphogenetic protein 1 (BMP1)/Tolloid-like proteinases from procollagen to generate triple-helix fibril monomers named tropocollagen (37). Finally, monomers assemble into macromolecular fibers by covalent crosslinks between certain lysine and hydroxylysine residues $(19,38)$. Fiber assembly is tightly regulated in vivo by a variety of molecules. Disruption in collagen fiber formation, structure and function by mutations leads to different bone pathology.

\section{Rare genetic disorders caused by $C O L 1 A 1$ and COL1A2 genes}

\subsection{Osteogenesis imperfecta}

\subsubsection{Phenotypic and genotypic characteristics of $O I$}

Osteogenesis imperfecta, also known as brittle bone disease, is a genetic connective tissue disorder with genetic and phenotypic diversity $(39,40)$. Skeletal features for OI are an increased susceptibility to bone fractures and reduced bone density, short stature, scoliosis and skull deformities. Extraskeletal characteristics include hearing and sight impairrment, dentinogenesis imperfecta, blue sclera, involvement of connective tissue, and cardiovascular and neurological abnormalities to some extent (Figure 2) $(41,42)$. OI has a broad clinical spectrum, ranging from mild to lethal forms. According to Sillence classification system, OI is divided into four types. Type I is the mildest form, patients with type I OI usually have family history, blue sclera, hearing impairment, near normal stature and 
rarely have dentinogenesis imperfecta. Type II OI is perinatal lethal, clinical characteristics include defective cranial ossification and severe skeletal deformity due to intrauterine rib, long bone fractures, and respiratory failure. Type III OI is the most severe form, affected individuals have triangular faces, frontal bossing, coxa vara, basilar invagination, early onset scoliosis, short stature, multiple fractures and long bone deformities $(43,44)$. Type IV is the moderately severe OI form, with overlapping phenotypes ranging from type I to type III. Generally, affected individuals experience broken fracture, mild short stature, dentinogenesis imperfecta, hearing loss, sclerae hue. Nearly $85 \%$ OI patients belong to type I to type IV, which is induced by COL1A1 and COL1A2 genes encoding proa1(I) and proa2(I) of type I procollagen in an autosomal-dominant inherited form $(45,46)$. Type VI to XIX are predominated by an autosomal-recessive form, and the number of pathogenic genes are multiple, while the total percentage for $\mathrm{OI}$ is no more than $20 \%$, the pathogenic genes for autosomalrecessive and $\mathrm{X}$-linked recessive forms includes CRTAP, LEPRE1, PPIB, BMP1, FKBP10, SERPINH1, SERINF1, WNT1, SP7, SERPINF1, TMEM38B, SPARC, MBTPS2 and TENT5A (39,47-49).

\subsubsection{COL1A1 and COL1A2 gene mutations of OI}

Generally, there's a relationship between genotype and phenotype for dominant OI caused by type I collagen genes. The molecular defect for type I OI is a null COL1A1 allele due to frameshifts or premature termination codons (PTCs), resulting in a decrease in the amount of structurally normal type I collagen. Splice site mutation can lead to mis-splicing with subsequent PTCs (50).

Substitutions and deletions in the triple helix region of type I collagen is the main mutation pattern for type II to type IV OI, predominated by substitutions of obligatory Gly-X-Y units. Substitutions of residues in this unit make procollagen folding more difficult, for these mismatches will further destabilize the triple helix. Triple-helix destabilization promotes procollagen misfolding, leads to retention of misfolded procollagen in the ER and HSP47 is unregulated (51). ER stress mediated by these mutations affect these cells producing type I collagen to some extent, resulting in structural and qualitative abnormal type I collagen (52-54). Glycine to serine substitution is most prevalent in all kinds of glycine changes. Meanwhile, Glycine to serine or alanine substitutions cause less damage than those of arginine, glutamic acid, aspartic acid or valine. Triplehelix folding of the later is much delayed. Glycine substitutions located in $\alpha 1$ (I) tend to be more severe than the $\alpha 2$ (I) chain $(55,56)$. Glycine substitutions at $\mathrm{C}$-terminal of collagen chains are more severe than that of N-terminal (57).

COL1A1 or COL1A2 mutations of OI are predominated by variations in the triple-helix region. OI Mutations in N- and C-propeptide or nearby are rare and commonly patients with these terminal mutations have overlapping clinical characteristics with other syndromes. Mutations in the C-propeptide cleavage The author confirm this is right with high bone mineral density $(58,59)$ and moderate to severe forms of OI are identified (60). For mutations in N-propeptide region, uncleaved N-propeptides will be enrolled into collagen fiber, and hence alter the fiber size, structure and strength $(61,62)$. For individuals who have mutations at these terminal regions of type I collagen, possible symptoms with other syndrome should be considered.

\subsection{Type I collagen gene related EDS}

\subsubsection{Cardiac-valvular type Ehlers-Danlos syndrome}

Ehlers-Danlos syndrome is a group of connective tissue disorders with phenotypic and genotypic variability. The modified classification based on Villefranche recognizes 13 different subtypes, most of which are linked to mutations in one of the genes encoding collagen proteins, enzymes for posttranslational modifications, myomatrix proteins and glycosaminoglycans $(63,64)$. Type I collagen-related EDS are rare, with no more than 50 patients in total $(65,66)$.

Cardiac-valvular type EDS (cvEDS) is characterized by cardiac valvular defects, joint hypermobility (generalized or restricted to small joints) and skin hyperextensibility, with atrophic scars, thin skin, and easy bruising. Minor criteria for diagnosis include inguinal hernia, pectus deformities, joint dislocations, and foot deformitiess $(63,67-69)$. The absence of pro $\alpha 2(\mathrm{I})$, and $\alpha 2(\mathrm{I})$ are observed in all reported seven cvEDS patients $(10,12,70,71)$. Biallelic COL1A2 mutations leads to nonsense-mediated mRNA decay and loss of function was suggested to be the molecular mechanism of cvEDS (10,71). Homozygous proa2(I) deficiency was reported also in type III OI patient, with recurrent fractures including rib fractures, popcorn deformities of the knee, wormian bone, generalized osteopenia, short stature, and hypermobile fingers. Collagen fibrils were mostly normal except for focal areas which were disorganized in size and shape (72). Patients with homozygous mutation of COL1A2 at intron 46 produced non-functional proa2(I), presenting EDS/ OI phenotypes including generalized joint hypermobility and foot deformities, pale blue sclerae and a mild increase in bone fragility (73). In all, deficiency of proa2(I) leads to different diseases and phenotypes and its mechanisms need to be further studied.

\subsubsection{The arthrochalasia type Ehlers-Danlos syndrome}

The arthrochalasia type of EDS, formerly known as VIIa and VIIb, with pathogenic genes of COL1A1 and 
COL1A2, respectively. It is different from other types of EDS by major diagnostic criteria of typical congenital hip dislocation, generalized joint laxity with multiple dislocations/subluxations, and skin hyperextensibility. Minor criteria for diagnosis include tissue fragility, easy bruising, muscle hypotonina, kyphoscoliosis and radiologically mild osteopenia $(63,68,74,75)$.

Generally, COL1A1 and COL1A2 gene mutations for aEDS patients are clustered around the exon/ intron 5 and 6 region. Heterozygous in frame deletion of N-telopeptide of either proa1(I) or proa2(I) are a common genetic basis for aEDS. Splice site mutations of intron 5 and 6 of COL1A1 or COL1A2 gene lead to whole or partial skipping of exon $6(76,77)$. N-telopeptide links N-propeptide to the triple-helix domain. It contains cleavage site for procollagen-N-proteinase and crosslinking lysyl residue. Thus, deletion of N-telopeptide results in incomplete cleavage of procollagen and defective cross-linking. N-propeptide is incorporated within fibrils to form accumulated pNcollagen $(77,78)$.

Until now, over 30 aEDS have been reported and most mutations are caused by $C O L 1 A 2$ mutation $(14,65,66,74,77-87)$. It seems that aEDS caused by COL1A1 have more severe phenotypes than COL1A2 gene. Collagen fibrils in aEDS patients are more loosely and irregular organized, vary widely in diameter and present with ragged cross-sections in outline. This is extremely severe in patients with EDS VIIa compared to EDS VIIb patients (75).

Patient with exon 5 and exon 6 deletion of COL1A1 presented with bilateral dislocation of the hips, extreme joint hypermobility, femoral fracture and normal skin at birth (81). The $3^{\prime}$ acceptor splice site COL1A1 IVS5 $-1 \mathrm{G}>\mathrm{A}$ results in alternative splicing of exon 6 . Patients with this mutation have overlapping phenotypes resembling OI, including multiple fractures, wormian bones, generalized dentinogenesis imperfecta, severe kyphoscoliosis, and relative short stature. The skin was generally lax, redundant, and hyperextensible, but without scarring or bruising (81). Mutation of c.543G $>$ A (p.Met181Ile) in the last nucleotide of exon 6 induced abnormal pre-mRNA splicing without exon 6 (15). One of the probands with this mutation presented with typical aEDS symptoms and a fracture history (86). Patients with EDS VIIb are more prevalent than VIIa type and fractures are rarely documented (88). Clinically, there is some overlap between OI and EDS type VII, especially for EDS type VIIa as mentioned above. In reverse, hypermobility is also seen in OI patients (88), overlapping with aEDS.

\subsubsection{OI/EDS}

Patients with OI/EDS combined clinical symptoms of OI as well as EDS. OI/EDS mutations are restricted to the region of $\mathrm{N}$-terminal and $\mathrm{C}$-terminal of type I collagen. The N-terminal of type I collagen triple helix region, corresponds to exons 7-14 (89-94). The first 85 amino acids at $\mathrm{N}$-terminal of each chain of type I collagen helix are called the $\mathrm{N}$-anchor, which is vital for proper folding and stability of $\mathrm{N}$-terminal end of the triple helix. Mutations at this region lead to incomplete or delayed N-propeptide cleavage and association of pNcollagen with fibrils (89). OI/EDS patients with this type of mutation usually presented mainly by generalized joint hyperlaxity and skin hyperextensibility, early progressive scoliosis as well as mild to lethal OI symptoms including relatively short stature, blue sclerae, infrequent or frequent bone fracture and different levels of osteopenia (Figure 3) (89-91,93). We found ptosis

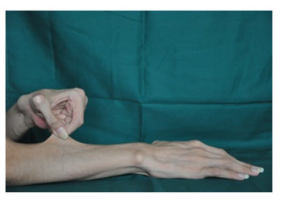

A

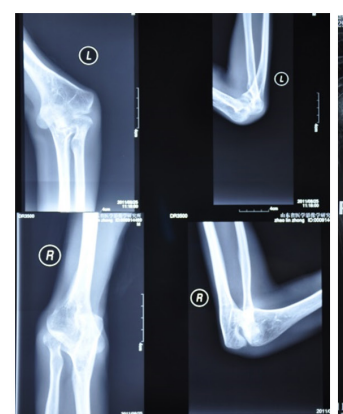

$\mathrm{E}$

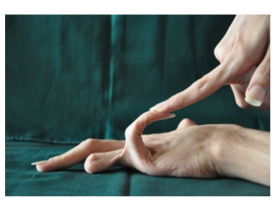

B

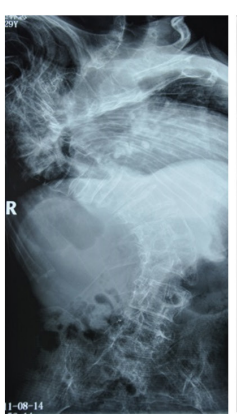

$\mathrm{F}$

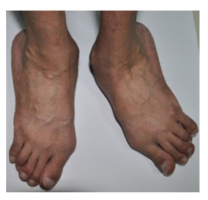

C

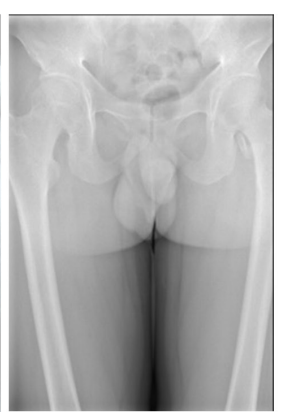

G

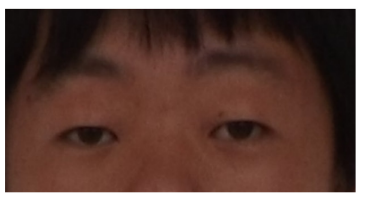

D

Figure 3. Clinical symptoms (A-D) and radiographic characteristics (E-G) for OI/EDS. (A), hyperextensible skin; (B), hypermobile joint; (C), pes varus; (D), bilateral congenital ptosis; (E), subluxation of elbow (28 years old man); (F), scoliosis and compression of spinal vertebrae; $(\mathbf{G})$, relatively normal cortical bone. 
in one individual with family history existed in $\mathrm{OI} /$ EDS with the mutation of c.3521C $>\mathrm{T}$ (Ala1174Val) in COL1A1; this symptom is also displayed in type XV OI caused by the Wnt1 gene (95-97).

Splice site mutations lead to partial or whole exon skipping similar to aEDS, with atypical or mild form of OI. Mosaic deletion of 9 nucleotides from 3150 to 3158 in the coding region of exon 44 results in in frame deletion of three amino acids was identified in a patient's cultured fibroblasts. The patient with this mutation has mild clinical EDS and OI symptoms (98). Exon duplication with the addition of 477 amino acids (p.Gly181_Lys657dup) to the triple helical domain of proa2(I) chain leads to relatively mild OI/EDS symptoms (91). Patients with missense mutations of c.563G $>$ A (p.Gly188Asp), c.607G $>$ T (p.Gly203Cys) in COL1A1 and c.326G $>$ A (p.Gly109Asp) in COL1A2 all showed cardiovascular problems, which was not observed in patients with mutations of c.587G $>\mathrm{T}$ (p.Gly196Val) in COL1A1 (90). For c.671G $>$ A (p.Gly224Asp) mutation of COL1A1, patients have severe type III OI and moderate EDS, collagen fibrils are organized irregularly, with decreased fibril density and decreased fibril diameter (93).

OI/EDS patients with mutation in C-terminal of type I collagen genes (exon 37 to 51) have broad clinical severity. Substitution of Ala1174Val, Arg1036Cys and Met 1264 Val presents milder OI signs $(95,99)$. Met1264Val substitution located at the prod1(I) of C-propeptide is supposed to impede C-propeptide folding and chain association (99). Also, OI patients in C-terminal of type I collagen genes have various phenotypes from mild to lethal forms.

One special patient with OI/EDS was identified owing to c.4006-1G > A mutation in COL1A1 and biallelic missense variants in TNXB (p.Val1213Ile, p.Gly2592Ser), he presented with severe muscular hypotonia, multiple fractures, and joint hyperflexibility (100). Homozygous mutation of splice site IVS 46 $+2 \mathrm{~T}>\mathrm{C}$ caused non-functional COL1A2 alleles, patient with this mutation showed clinical features of generalized joint hypermobility, foot deformities, muscle hypotonia, blue sclerae and fracture history (73).

\subsubsection{Caffey disease}

Caffey disease, also known as infantile cortical hyperostosis ( $\mathrm{ICH})$, is caused by COL1A1 gene mutation of c.3040C $>\mathrm{T}$ and leads to an arginine to cysteine substitution at position 836 . It rarely appears after 5 months of age and generally is restored spontaneously by 2 years old. Cortical thickening (hyperostosis) and subperiosteal new bone formation are the main findings of radiography. Tender swelling of long bone and inflammatory reactions often accompany the illness (101). Short stature and persistent bony deformities in 5 individuals from a three-generation Thai family are reported, which expands phenotypes of Caffey disease (102). Lethal or severe prenatal Caffey disease, complied with polyhydramnios, long bone deformity, and rib fractures, which could be misdiagnosed as lethal osteogenesis imperfecta (103-105). Two Caffey disease patients were reported to have overlapping phenotypes of joint hyperlaxity, hyperextensible skin and inguinal hernias resembling type III EDS (13).

Molecular mechanisms for Caffey disease are still unclear. Mutation of c.3040C $>$ T locates in the sequence of interleukin-2 binding site and the amyloid protein precursor (APP), the gap region of major ligand binding regions (106-108). Arg836Cys substitution leads to increased disulfide crosslinking within or between collagen fibrils. Hence, widened and less densely packed collagen fibrils was observed from cultured skin fibroblast from Caffey disease (13). Meanwhile, thermal stability of collagen is reduced when an arginine residue was replaced in the $\mathrm{X}$ position of classic Gly$\mathrm{X}-\mathrm{Y}$ repeating pattern of triple helix collagen (109). It is also proposed that this typical mutation may regulate COX2/PGE axis mediated by unfolded protein response (110).

\section{Conclusion}

In conclusion, genetic and phenotypic overlap of OI, aEDS, cvEDS and Caffey diseases caused by type I collagen genes are outlined. Position preference mutations in COL1A1 and COL1A2 genes are highly related with typical phenotypes and diseases with different molecular mechanisms. Mutations of aEDS are limited to intron 5 and 6 of type I collagen genes. OI/EDS mutations locate predominately in the C-terminal and N-terminal region of exon 7 to exon 14 . Considering the overlap mutation distribution of $\mathrm{OI}$ and EDS, it is a challenge to define disease with atypical phenotypes and atypical mutation distribution in type I collagen genes. Hence, clinical symptoms in detail for these diseases are extremely valuable. Meanwhile, to further analyze the heterozygosity in diseases like Caffey disease, which have a p.Gly188Asp mutation, as well as other diseases presenting clinical manifestations with the same pathogenic gene mutations, penetrance, expressivity and epigenetic regulation inherence should be considered and combined with phenotype/genotypes of rare genetic syndromes. In all, genotypic and phenotypic relationships and molecular mechanisms for type I collagen- related inherited diseases will be further enriched and revealed as the number of rare diseases cases increases. Novel methods for classification will be useful for identification of rare diseases with atypical symptoms.

\section{Acknowledgements}

This project was supported by Grants-in-Aid from 
the Shandong government (2016ZDJS07A10, 2016GSF201222 and 2015ZRC03171).

\section{References}

1. Prockop DJ, Kivirikko KI. Collagens: Molecular biology, diseases, and potentials for therapy. Annu Rev Biochem. 1995; 64:403-434.

2. Burgeson RE, Nimni ME. Collagen types. Molecular structure and tissue distribution. Clin Orthop Relat Res. 1992;250-272.

3. Bruckner P, van der Rest M. Structure and function of cartilage collagens. Microsc Res Tech. 1994; 28:378-384.

4. Kelly J, Tanaka S, Hardt T, Eikenberry EF, Brodsky B. Fibril-forming collagens in lamprey. J Biol Chem. . 1988; 263:980-987.

5. Brodsky B, Eikenberry EF. Characterization of fibrous forms of collagen. Methods Enzymol. 1982; 82 Pt A:127174.

6. Jimenez SA, Bashey RI, Benditt M, Yankowski R. Identification of collagen $\alpha 1$ (I) trimer in embryonic chick tendons and calvaria. Biochem Biophys Res Commun. 1977; 78:1354-1361.

7. Shapiro FD, Eyre DR. Collagen polymorphism in extracellular matrix of human osteosarcoma. J Natl Cancer Inst. 1982; 69:1009-1016.

8. Makareeva E, Han S, Vera JC, Sackett DL, Holmbeck K, Phillips CL, Visse R, Nagase H, Leikin S. Carcinomas contain a matrix metalloproteinase-resistant isoform of type I collagen exerting selective support to invasion. Cancer Res. 2010; 70:4366-4374.

9. Rojkind M, Giambrone MA, Biempica L. Collagen types in normal and cirrhotic liver. Gastroenterology. 1979; 76:710-719.

10. Malfait F, Symoens S, Coucke P, Nunes L, De Almeida S, De Paepe A. Total absence of the $\alpha 2$ (I) chain of collagen type I causes a rare form of Ehlers-Danlos syndrome with hypermobility and propensity to cardiac valvular problems. J Med Genet. 2006; 43:e36.

11. Chipman SD, Sweet HO, McBride DJ, Jr., Davisson MT, Marks SC, Jr., Shuldiner AR, Wenstrup RJ, Rowe DW, Shapiro JR. Defective pro $\alpha$ 2(I) collagen synthesis in a recessive mutation in mice: A model of human osteogenesis imperfecta. Proc Natl Acad Sci U S A. 1993; 90:1701-1705.

12. Schwarze U, Hata R, McKusick VA, Shinkai H, Hoyme HE, Pyeritz RE, Byers PH. Rare autosomal recessive cardiac valvular form of Ehlers-Danlos syndrome results from mutations in the COL1A2 gene that activates the nonsense-mediated RNA decay pathway. Am J Hum Genet. 2004; 74:917-930.

13. Gensure RC, Makitie O, Barclay C, Chan C, Depalma SR, Bastepe M, Abuzahra H, Couper R, Mundlos S, Sillence D, Ala Kokko L, Seidman JG, Cole WG, Juppner H. A novel COL1A1 mutation in infantile cortical hyperostosis (Caffey disease) expands the spectrum of collagen-related disorders. J Clin Invest. 2005; 115:1250-1257.

14. Cole WG, Chan D, Chambers GW, Walker ID, Bateman JF. Deletion of 24 amino acids from the pro- $\alpha$ 1(I) chain of type I procollagen in a patient with the Ehlers-Danlos syndrome type VII. J Biol Chem. 1986; 261:5496-5503.

15. Weil D, D'Alessio M, Ramirez F, de Wet W, Cole WG, Chan D, Bateman JF. A base substitution in the exon of a collagen gene causes alternative splicing and generates a structurally abnormal polypeptide in a patient with Ehlers-Danlos syndrome type VII. EMBO J. 1989; 8:1705-1710.

16. Eyre DR, Shapiro FD, Aldridge JF. A heterozygous collagen defect in a variant of the Ehlers-Danlos syndrome type VII. Evidence for a deleted aminotelopeptide domain in the pro- $\alpha$ 2(I) chain. J Biol Chem. 1985; 260:11322-11329.

17. Xie P, Liu B, Zhang L, Chen R, Yang B, Dong J, Rong L. Association of COL1A1 polymorphisms with osteoporosis: a meta-analysis of clinical studies. Int J Clin Exp Med. 2015; 8:14764-14781.

18. Kielty CM, Grant ME. The collagen family : structure, assembly, and organization in the extracellular matrix. In: Connective Tissue and Its Heritable Disorders: Molecular, Genetic, and Medical Aspects, Second Edition (Royce PM, Steinmann B, eds.). Wiley-Liss, Inc, 2002; pp. 159-219.

19. Sorushanova A, Delgado LM, Wu Z, Shologu N, Kshirsagar A, Raghunath R, Mullen AM, Bayon Y, Pandit A, Raghunath M, Zeugolis DI. The Collagen Suprafamily: From Biosynthesis to Advanced Biomaterial Development. Adv Mater. 2019; 31:e1801651.

20. Myllyharju J, Kivirikko KI. Collagens, modifying enzymes and their mutations in humans, flies and worms. Trends Genet. 2004; 20:33-43.

21. Engel J, Prockop DJ. The zipper-like folding of collagen triple helices and the effects of mutations that disrupt the zipper. Annu Rev Biophys Biophys Chem. 1991; 20:137152.

22. Lamande SR, Bateman JF. Procollagen folding and assembly: The role of endoplasmic reticulum enzymes and molecular chaperones. Semin Cell Dev Biol. 1999; 10:455-464.

23. Bourhis JM, Mariano N, Zhao Y, Harlos K, Exposito JY, Jones EY, Moali C, Aghajari N, Hulmes DJ. Structural basis of fibrillar collagen trimerization and related genetic disorders. Nat Struct Mol Biol. 2012; 19:1031-1036.

24. Bulleid NJ. Solving the mystery of procollagen chain selectivity. Nat Struct Mol Biol. 2012; 19:977-978.

25. Ellgaard L, Ruddock LW. The human protein disulphide isomerase family: substrate interactions and functional properties. EMBO Rep. 2005; 6:28-32.

26. Malhotra JD, Kaufman RJ. The endoplasmic reticulum and the unfolded protein response. Semin Cell Dev Biol. 2007; 18:716-731.

27. Yoshida H. ER stress and diseases. FEBS J. 2007; 274:630-658.

28. Chessler SD, Byers PH. BiP binds type I procollagen pro $\alpha$ chains with mutations in the carboxyl-terminal propeptide synthesized by cells from patients with osteogenesis imperfecta. J Biol Chem. 1993; 268:1822618233.

29. Fitzgerald J, Lamande SR, Bateman JF. Proteasomal degradation of unassembled mutant type I collagen proa1(I) chains. J Biol Chem. 1999; 274:27392-27398.

30. Khan ES, Sankaran S, Paez JI, Muth C, Han MKL, Del Campo A. Photoactivatable Hsp47: A Tool to Regulate Collagen Secretion and Assembly. Adv Sci (Weinh). 2019; 6:1801982.

31. Duran I, Martin JH, Weis MA, Krejci P, Konik P, Li B, Alanay Y, Lietman C, Lee B, Eyre D, Cohn DH, Krakow D. A Chaperone Complex Formed by HSP47, FKBP65, and BiP Modulates Telopeptide Lysyl Hydroxylation of Type I Procollagen. J Bone Miner Res. 2017; 32:1309- 
1319.

32. Saito K, Maeda M. Not just a cargo receptor for large cargoes; an emerging role of TANGO1 as an organizer of ER exit sites. J Biochem. 2019; pii: mvz036. doi: $10.1093 / \mathrm{jb} / \mathrm{mvz} 036$

33. Yuan L, Kenny SJ, Hemmati J, Xu K. Schekman R. TANGO1 and SEC12 are copackaged with procollagen I to facilitate the generation of large COPII carriers. Proc Natl Acad Sci U S A. 2018; 115:E12255-e12264.

34. Ke H, Feng Z, Liu M, Sun T, Dai J, Ma M, Liu LP, Ni JQ, Pastor-Pareja JC. Collagen secretion screening in Drosophila supports a common secretory machinery and multiple Rab requirements. J Genet Genomics. 2018; pii: S1673-8527(18)30097-3.

35. Canty EG, Lu Y, Meadows RS, Shaw MK, Holmes DF, Kadler KE. Coalignment of plasma membrane channels and protrusions (fibripositors) specifies the parallelism of tendon. J Cell Biol. 2004; 165:553-563.

36. Canty-Laird EG, Lu Y, Kadler KE. Stepwise proteolytic activation of type I procollagen to collagen within the secretory pathway of tendon fibroblasts in situ. Biochem J. 2012; 441:707-717.

37. Hopkins DR, Keles S, Greenspan DS. The bone morphogenetic protein 1/Tolloid-like metalloproteinases. Matrix Biol. 2007; 26:508-523.

38. Gelse K, Poschl E, Aigner T. Collagens - structure, function, and biosynthesis. Adv Drug Deliv Rev. 2003; 55:1531-1546.

39. Marini JC, Forlino A, Bachinger HP, Bishop NJ, Byers PH, Paepe A, Fassier F, Fratzl-Zelman N, Kozloff KM, Krakow D, Montpetit K, Semler O. Osteogenesis imperfecta. Nat Rev Dis Primers. 2017; 3:17052.

40. Lu Y, Ren X. Osteogenesis imperfecta. In: Osteopathic Internal Medicine (Liu Z, ed. Chemical Industry Publisher, Beijing 2015; pp. 789-799. (in Chinese)

41. Sam JE, Dharmalingam M. Osteogenesis Imperfecta. Indian J Endocrinol Metab. 2017; 21:903-908.

42. Lu Y, Ren X, Wang Y, Han J. Molecular mechanisms of osteogenesis imperfecta. Progress in Biochemistry and Biophysics. 2015; 42:511-518. (in Chinese)

43. Rauch F, Lalic L, Roughley P, Glorieux FH. Relationship between genotype and skeletal phenotype in children and adolescents with osteogenesis imperfecta. J Bone Miner Res. 2010; 25:1367-1374.

44. Forlino A, Cabral WA, Barnes AM, Marini JC. New perspectives on osteogenesis imperfecta. Nat Rev Endocrinol. 2011; 7:540-557.

45. Sillence D. Osteogenesis imperfecta: An expanding panorama of variants. Clin Orthop Relat Res. 1981;11-25.

46. Marini JC, Blissett AR. New genes in bone development: what's new in osteogenesis imperfecta. J Clin Endocrinol Metab. 2013; 98:3095-3103.

47. Doyard M, Bacrot S, Huber C, et al. FAM46A mutations are responsible for autosomal recessive osteogenesis imperfecta. J Med Genet. 2018; 55:278-284.

48. Lindert U, Cabral WA, Ausavarat S, et al. MBTPS2 mutations cause defective regulated intramembrane proteolysis in X-linked osteogenesis imperfecta. Nat Commun. 2016; 7:11920.

49. Mendoza-Londono R, Fahiminiya S, Majewski J, et al. Recessive osteogenesis imperfecta caused by missense mutations in SPARC. Am J Hum Genet. 2015; 96:979985.

50. Subramanian S, Viswanathan VK. Osteogenesis Imperfecta. In: StatPearls (StatPearls Publishing StatPearls
Publishing LLC., Treasure Island (FL), 2019.

51. Costell M, Gustafsson E, Aszodi A, Morgelin M, Bloch W, Hunziker E, Addicks K, Timpl R, Fassler R. Perlecan maintains the integrity of cartilage and some basement membranes. J Cell Biol. 1999; 147:1109-1122.

52. Forlino A, Tani C, Rossi A, Lupi A, Campari E, Gualeni B, Bianchi L, Armini A, Cetta G, Bini L, Marini JC. Differential expression of both extracellular and intracellular proteins is involved in the lethal or nonlethal phenotypic variation of BrtlIV, a murine model for osteogenesis imperfecta. Proteomics. 2007; 7:1877-1891.

53. Forlino A, Kuznetsova NV, Marini JC, Leikin S. Selective retention and degradation of molecules with a single mutant $\alpha 1$ (I) chain in the Brtl IV mouse model of OI. Matrix Biol. 2007; 26:604-614.

54. Bateman JF, Boot-Handford RP, Lamande SR. Genetic diseases of connective tissues: Cellular and extracellular effects of ECM mutations. Nat Rev Genet. 2009; 10:173183.

55. Beck K, Chan VC, Shenoy N, Kirkpatrick A, Ramshaw JA, Brodsky B. Destabilization of osteogenesis imperfecta collagen-like model peptides correlates with the identity of the residue replacing glycine. Proc Natl Acad Sci U S A. 2000; 97:4273-4278.

56. Xiao J, Cheng H, Silva T, Baum J, Brodsky B. Osteogenesis imperfecta missense mutations in collagen: structural consequences of a glycine to alanine replacement at a highly charged site. Biochemistry. 2011; 50:10771-10780.

57. Montpetit K, Palomo T, Glorieux FH, Fassier F, Rauch F. Multidisciplinary treatment of severe osteogenesis imperfecta: Functional outcomes at skeletal maturity. Arch Phys Med Rehabil. 2015; 96:1834-1839.

58. Lindahl K, Barnes AM, Fratzl-Zelman N, et al. COL1 $\mathrm{C}$-propeptide cleavage site mutations cause high bone mass osteogenesis imperfecta. Hum Mutat. 2011; 32:598609.

59. Asharani PV, Keupp K, Semler O, et al. Attenuated $B M P 1$ function compromises osteogenesis, leading to bone fragility in humans and zebrafish. Am J Hum Genet. 2012; 90:661-674.

60. Lu Y, Ren X, Wang Y, Li T, Li F, Wang S, Xu C, Wu G, Li H, Li G, Zhao F, Wang Z, Mo X, Han J. Mutational and structural characteristics of four novel heterozygous C-propeptide mutations in the proal(I) collagen gene in Chinese osteogenesis imperfecta patients. Clin Endocrinol (Oxf). 2014; 80:524-531.

61. Romanic AM, Adachi E, Hojima Y, Engel J, Prockop DJ. Polymerization of pNcollagen I and copolymerization of pNcollagen I with collagen I. A kinetic, thermodynamic, and morphologic study. J Biol Chem. 1992; 267:2226522271.

62. Hulmes DJ, Kadler KE, Mould AP, Hojima Y, Holmes DF, Cummings C, Chapman JA, Prockop DJ. Pleomorphism in type I collagen fibrils produced by persistence of the procollagen N-propeptide. J Mol Biol. 1989; 210:337-345.

63. Bloom L, Byers P, Francomano C, Tinkle B, Malfait F; Steering Committee of The International Consortium on the Ehlers-Danlos Syndromes. The international consortium on the Ehlers-Danlos syndromes. Am J Med Genet C Semin Med Genet. 2017; 175:5-7.

64. Cortini F, Villa C, Marinelli B, Combi R, Pesatori AC, Bassotti A. Understanding the basis of Ehlers-Danlos syndrome in the era of the next-generation sequencing. 
Arch Dermatol Res. 2019; 311:265-275.

65. Dalgleish R. The human type I collagen mutation database. Nucleic Acids Res. 1997; 25:181-187.

66. Dalgleish R. The human type I collagen mutation database. Nucleic Acids Res. 1998; 26:253-255.

67. Shohet I, Rosenbaum I, Frand M, Duksin D, Engelberg $\mathrm{S}$, Goodman RM. Cardiovascular complications in the Ehlers-Danlos syndrome with minimal external findings. Clin Genet. 1987; 31:148-152.

68. Malfait F, Francomano C, Byers P, et al. The 2017 international classification of the Ehlers-Danlos syndromes. Am J Med Genet C Semin Med Genet. 2017; 175:8-26.

69. Lu Y, Li H. Ehlers-Danlos syndrome. In: Osteopathic Internal Medicine (Liu Z, ed. Chemical Industry Publisher, Beijing 2015; pp. 800-807. (in Chinese)

70. Kojima T, Shinkai H, Fujita M, Morita E, Okamoto S. Case report and study of collagen metabolism in EhlersDanlos syndrome type II. J Dermatol. 1988; 15:155-160.

71. Guarnieri V, Morlino S, Di Stolfo G, Mastroianno S, Mazza T, Castori M. Cardiac valvular Ehlers-Danlos syndrome is a well-defined condition due to recessive null variants in COL1A2. Am J Med Genet A. 2019; 179:846-851.

72. Nicholls AC, Osse G, Schloon HG, Lenard HG, Deak S, Myers JC, Prockop DJ, Weigel WR, Fryer P, Pope FM. The clinical features of homozygous $\alpha$ 2(I) collagen deficient osteogenesis imperfecta. J Med Genet. 1984; 21:257-262.

73. Nicholls AC, Valler D, Wallis S, Pope FM. Homozygosity for a splice site mutation of the COL1A2 gene yields a non-functional pro( $\alpha) 2(\mathrm{I})$ chain and an EDS/OI clinical phenotype. J Med Genet. 2001; 38:132136.

74. Byers PH, Duvic M, Atkinson M, Robinow M, Smith LT, Krane SM, Greally MT, Ludman M, Matalon R, Pauker S, Quanbeck D, Schwarze U. Ehlers-Danlos syndrome type VIIA and VIIB result from splice-junction mutations or genomic deletions that involve exon 6 in the COL1A1 and COL1A2 genes of type I collagen. Am J Med Genet. 1997; 72:94-105.

75. Giunta C, Chambaz C, Pedemonte M, Scapolan S, Steinmann B. The arthrochalasia type of Ehlers-Danlos syndrome (EDS VIIA and VIIB): the diagnostic value of collagen fibril ultrastructure. Am J Med Genet A. 2008; 146a:1341-1346.

76. Cole WG, Evans R, Sillence DO. The clinical features of Ehlers-Danlos syndrome type VII due to a deletion of 24 amino acids from the pro $\alpha 1$ (I) chain of type I procollagen. J Med Genet. 1987; 24:698-701.

77. Weil D, Bernard M, Combates N, Wirtz MK, Hollister DW, Steinmann B, Ramirez F. Identification of a mutation that causes exon skipping during collagen premRNA splicing in an Ehlers-Danlos syndrome variant. J Biol Chem. 1988; 263:8561-8564.

78. Weil D, D'Alessio M, Ramirez F, Steinmann B, Wirtz MK, Glanville RW, Hollister DW. Temperaturedependent expression of a collagen splicing defect in the fibroblasts of a patient with Ehlers-Danlos syndrome type VII. J Biol Chem. 1989; 264:16804-16809.

79. Hass J, Hass R. Arthrochalasis multiplex congenita; congenital flaccidity of the joints. J Bone Joint Surg Am. 1958; 40-a:663-674.

80. Giunta C, Superti-Furga A, Spranger S, Cole WG, Steinmann B. Ehlers-Danlos syndrome type VII: clinical features and molecular defects. J Bone Joint Surg Am. 1999; 81:225-238.

81. Nicholls AC, Sher JL, Wright MJ, Oley C, Mueller RF, Pope FM. Clinical phenotypes and molecular characterisation of three patients with Ehlers-Danlos syndrome type VII. J Med Genet. 2000; 37:E33.

82. Chiodo AA, Hockey A, Cole WG. A base substitution at the splice acceptor site of intron 5 of the COL1A2 gene activates a cryptic splice site within exon 6 and generates abnormal type I procollagen in a patient with EhlersDanlos syndrome type VII. J Biol Chem. 1992; 267:63616369.

83. Whitaker IS, Rozen WM, Cairns SA, Howes J, Pope FM, Hamish Laing J. Molecular genetic and clinical review of Ehlers-Danlos Type VIIA: Implications for management by the plastic surgeon in a multidisciplinary setting. J Plast Reconstr Aesthet Surg. 2009; 62:589-594.

84. Vasan NS, Kuivaniemi H, Vogel BE, Minor RR, Wootton JA, Tromp G, Weksberg R, Prockop DJ. A mutation in the pro $\alpha 2$ (I) gene (COL1A2) for type I procollagen in Ehlers-Danlos syndrome type VII: evidence suggesting that skipping of exon 6 in RNA splicing may be a common cause of the phenotype. Am J Hum Genet. 1991; 48:305-317.

85. Watson RB, Wallis GA, Holmes DF, Viljoen D, Byers PH, Kadler KE. Ehlers Danlos syndrome type VIIB. Incomplete cleavage of abnormal type I procollagen by $\mathrm{N}$-proteinase in vitro results in the formation of copolymers of collagen and partially cleaved pNcollagen that are near circular in cross-section. J Biol Chem. 1992; 267:9093-9100.

86. D'Alessio M, Ramirez F, Blumberg BD, Wirtz MK, Rao VH, Godfrey MD, Hollister DW. Characterization of a COL1A1 splicing defect in a case of Ehlers-Danlos syndrome type VII: further evidence of molecular homogeneity. Am J Hum Genet. 1991; 49:400-406.

87. Pope FM, Nicholls AC, Palan A, Kwee ML, De Groot WP, Hausmann R. Clinical features of an affected father and daughter with Ehlers-Danlos syndrome type VIIB. Br J Dermatol. 1992; 126:77-82.

88. Klaassens M, Reinstein E, Hilhorst-Hofstee Y, Schrander JJ, Malfait F, Staal H, ten Have LC, Blaauw J, Roggeveen HC, Krakow D, De Paepe A, van Steensel MA, Pals G, Graham JM Jr, Schrander-Stumpel CT. Ehlers-Danlos arthrochalasia type (VIIA-B) - expanding the phenotype: from prenatal life through adulthood. Clin Genet. 2012; 82:121-130.

89. Cabral WA, Makareeva E, Colige A, Letocha AD, Ty JM, Yeowell HN, Pals G, Leikin S, Marini JC. Mutations near amino end of $\alpha 1$ (I) collagen cause combined osteogenesis imperfecta/Ehlers-Danlos syndrome by interference with N-propeptide processing. J Biol Chem. 2005; 280:1925919269.

90. Malfait F, Symoens S, Goemans N, Gyftodimou Y, Holmberg E, Lopez-Gonzalez V, Mortier G, Nampoothiri $S$, Petersen MB, De Paepe A. Helical mutations in type I collagen that affect the processing of the aminopropeptide result in an Osteogenesis Imperfecta/EhlersDanlos Syndrome overlap syndrome. Orphanet J Rare Dis. 2013; 8:78.

91. Raff ML, Craigen WJ, Smith LT, Keene DR, Byers PH. Partial COL1A2 gene duplication produces features of osteogenesis imperfecta and Ehlers-Danlos syndrome type VII. Hum Genet. 2000; 106:19-28.

92. Nicholls AC, Oliver J, Renouf DV, Heath DA, Pope 
FM. The molecular defect in a family with mild atypical osteogenesis imperfecta and extreme joint hypermobility: exon skipping caused by an 11-bp deletion from an intron in one COL1A2 allele. Hum Genet. 1992; 88:627-633.

93. Lu Y, Wang Y, Rauch F, Li H, Zhang Y, Zhai N, Zhang J, Ren X, Han J. Osteogenesis imperfecta type III/EhlersDanlos overlap syndrome in a Chinese man. Intractable Rare Dis Res. 2018; 7:37-41.

94. Cabral WA, Makareeva E, Letocha AD, Scribanu N, Fertala A, Steplewski A, Keene DR, Persikov AV, Leikin S, Marini JC. Y-position cysteine substitution in type I collagen $(\alpha 1(\mathrm{I}) \mathrm{R} 888 \mathrm{C} / \mathrm{p} . \mathrm{R} 1066 \mathrm{C})$ is associated with osteogenesis imperfecta/Ehlers-Danlos syndrome phenotype. Hum Mutat. 2007; 28:396-405.

95. Shi X, Lu Y, Wang Y, Zhang YA, Teng Y, Han W, Han Z, Li T, Chen M, Liu J, Fang F, Dou C, Ren X, Han $\mathrm{J}$. Heterozygous mutation of c. $3521 \mathrm{C}>\mathrm{T}$ in $\mathrm{COL} 1 \mathrm{Al}$ may cause mild osteogenesis imperfecta/Ehlers-Danlos syndrome in a Chinese family. Intractable Rare Dis Res. 2015; 4:49-53.

96. Lu Y, Ren X, Wang Y, Bardai G, Sturm M, Dai Y, Riess O, Zhang Y, Li H, Li T, Zhai N, Zhang J, Rauch F, Han J. Novel WNT1 mutations in children with osteogenesis imperfecta: Clinical and functional characterization. Bone. 2018; 114:144-149.

97. Lu Y, Ren X, Wang Y, Han J. Wnt Signaling Associated Human Diseases. Nov Tech Arthritis Bone Res. 2018; 3:555607.

98. Symoens S, Steyaert W, Demuynck L, De Paepe A, Diderich KE, Malfait F, Coucke PJ. Tissue-specific mosaicism for a lethal osteogenesis imperfecta COL1A1 mutation causes mild OI/EDS overlap syndrome. Am J Med Genet A. 2017; 173:1047-1050.

99. Symoens S, Nuytinck L, Legius E, Malfait F, Coucke PJ, De Paepe A. Met>Val substitution in a highly conserved region of the pro- $\alpha 1(\mathrm{I})$ collagen $\mathrm{C}$-propeptide domain causes alternative splicing and a mild EDS/OI phenotype. J Med Genet. 2004; 41:e96.

100. Mackenroth L, Fischer-Zirnsak B, Egerer J, Hecht J, Kallinich T, Stenzel W, Spors B, von Moers A, Mundlos S, Kornak U, Gerhold K, Horn D. An overlapping phenotype of Osteogenesis imperfecta and Ehlers-Danlos syndrome due to a heterozygous mutation in COL1A1 and biallelic missense variants in TNXB identified by whole exome sequencing. Am J Med Genet A. 2016; 170a:1080-1085.

101. Kirby K, Wright JE. Infantile Cortical Hyperostosis (Caffey Disease). In: StatPearls (StatPearls Publishing StatPearls Publishing LLC., Treasure Island (FL), 2019.

102. Suphapeetiporn K, Tongkobpetch S, Mahayosnond A, Shotelersuk V. Expanding the phenotypic spectrum of Caffey disease. Clin Genet. 2007; 71:280-284.

103. Kamoun-Goldrat A, Martinovic J, Saada J, Sonigo-Cohen P, Razavi F, Munnich A, Le Merrer M. Prenatal cortical hyperostosis with COL1A1 gene mutation. Am J Med Genet A. 2008; 146a:1820-1824.

104. de Jong G, Muller LM. Perinatal death in two sibs with infantile cortical hyperostosis (Caffey disease). Am J Med Genet. 1995; 59:134-138.

105. Lecolier B, Bercau G, Gonzales M, Afriat R, Rambaud D, Mulliez N, de Kermadec S. Radiographic, haematological, and biochemical findings in a fetus with Caffey disease. Prenat Diagn. 1992; 12:637-641.

106. Somasundaram R, Ruehl M, Tiling N, Ackermann R, Schmid M, Riecken EO, Schuppan D. Collagens serve as an extracellular store of bioactive interleukin 2. J Biol Chem. 2000; 275:38170-38175.

107. Beher D, Hesse L, Masters CL, Multhaup G. Regulation of amyloid protein precursor (APP) binding to collagen and mapping of the binding sites on APP and collagen type I. J Biol Chem. 1996; 271:1613-1620.

108. Di Lullo GA, Sweeney SM, Korkko J, Ala-Kokko L, San Antonio JD. Mapping the ligand-binding sites and disease-associated mutations on the most abundant protein in the human, type I collagen. J Biol Chem. 2002; 277:4223-4231.

109. Persikov AV, Ramshaw JA, Brodsky B. Collagen model peptides: Sequence dependence of triple-helix stability. Biopolymers. 2000; 55:436-450.

110. Nistala H, Makitie O, Juppner H. Caffey disease: new perspectives on old questions. Bone. 2014; 60:246-251.

(Received April 8, 2019; Revised May 24, 2019; Accepted May 30, 2019 